\title{
PENGARUH BUDAYA ORGANISASI DAN KOMITMEN ORGANISASIONAL TERHADAP KINERJA PEGAWAI KANTOR PELAYANAN PAJAK PRATAMA BIREUEN
}

\author{
Denny Firmansyah ${ }^{1}$; Evida Zanora ${ }^{2}$ \\ ${ }^{1}$ Dosen Program Studi Administrasi Bisnis Fakultas Ilmu Sosial dan Ilmu Politik Universitas Almuslim \\ ${ }^{2}$ Mahasiswa Program Studi Administrasi Bisnis Fakultas Ilmu Sosial dan Ilmu Politik Universitas Almuslim \\ Email: manggislangsa@gmail.com
}

Diterima 25 Mei 2021/Disetujui 5 Juni 2021

\begin{abstract}
ABSTRAK
Penelitian ini bertujuan untuk mengetahui seberapa besar pengaruh budaya organisasi dan komitmen organisasional terhadap kinerja pegawai Kantor Pelayanan Pajak Pratama Bireuen. Metode penelitian yang digunakan dalam penelitian ini adalah metode kuantitatif. Penelitian dilaksanakan pada Kantor Pelayanan Pajak Pratama Bireuen. Objek penelitian adalah pegawai pada Kantor Pelayanan Pajak Pratama Bireuen. Sedangkan sampel penelitian adalah 30 pegawai pada Kantor Pelayanan Pajak Pratama Bireuen. Data penelitian bersumber dari: 1) data primer, yaitu data yang diperoleh secara langsung dari hasil wawancara, observasi dan kuesioner yang disebarkan kepada sejumlah sampel responden sesuai target sasaran dan mewakili seluruh sampel penelitian, yaitu pegawai Kantor Pelayanan Pajak Pratama Bireuen; 2) data sekunder, yaitu data yang diperoleh dari pihak lain secara tidak langsung, berhubungan dengan penelitian yang dilakukan berupa sejarah dan ruang likup perusahaan, struktur organisasi, buku, literatur, artikel, serta situs di internet. Teknik analisis data menggunakan regresi berganda, koefisien determinasi $\left(\mathrm{r}^{2}\right)$, dan uji hipotesis yaitu uji parsial dan uji simultan. Berdasarkan hasil dan pembahasan penelitian dapat disimpulkan bahwa: 1) budaya organisasi secara parsial berpengaruh terhadap kinerja pegawai Kantor Pelayanan Pajak Pratama Bireuen dengan nilai $t_{\text {hitung }}$ sebesar 2,456 dan nilai $\mathrm{t}_{\text {tabel }}$ sebesar 1,70 artinya 2,456 >1,70 dengan nilai probabilitas sebesar 0,021 , menandakan bahwa $\mathrm{H}_{\mathrm{o}}$ ditolak dan $\mathrm{H}_{\mathrm{a}}$ diterima, maka terdapat pengaruh positif dari budaya organisasi terhadap kinerja pegawai; 2) komitmen organisasional secara parsial berpengaruh terhadap kinerja pegawai Kantor Pelayanan Pajak Pratama Bireuen dengan nilai $t_{\text {hitung }}$ sebesar 3,496 dan nilai $t_{\text {tabel }}$ sebesar 1,70 artinya $3,496>1,70$ dengan nilai probabilitas sebesar 0,002 , menandakan bahwa $\mathrm{H}_{\mathrm{o}}$ ditolak dan $\mathrm{H}_{\mathrm{a}}$ diterima, maka terdapat pengaruh positif dari komitmen organisasional terhadap kinerja pegawai; 3) budaya organisasi dan komitmen organisasional secara simultan berpengaruh terhadap kinerja pegawai Kantor Pelayanan Pajak Pratama Bireuen dengan nilai $F_{\text {hitung }}$ sebesar 7,717 dan nilai $\mathrm{F}_{\text {tabel }}$ sebesar 3,35 dengan nilai signifikan 0,000, menandakan bahwa $\mathrm{H}_{\mathrm{o}}$ ditolak $\mathrm{H}_{\mathrm{a}}$ diterima.
\end{abstract}

\section{Kata kunci: budaya organisasi, komitmen organisasional, kinerja pegawai}

\section{PENDAHULUAN}

Modernisasi Direktorat Jenderal Pajak mulai diterapkan pada tahun 2017, salah satunya dengan modernisasi Kantor Pelayanan Pajak Pratama yang telah mencapai kemajuan signifikan. Bahkan, hampir semua Kantor Pelayanan Pajak Pratama di Aceh telah menjadi Kantor Pelayanan Pajak Pratama modern dan hampir semua kabupaten memiliki Kantor Pelayanan Pajak Pratama. Kantor Pelayanan Pajak Pratama Bireuen adalah sebuah lembaga pemerintah yang bertugas mengawasi dan melayani masyarakat dalam hal perpajakan yang berada di Kabupaten Bireuen. Kantor Pelayanan Pajak Pratama Bireuen mulai beroperasi pada tanggal 9 September 2008 sesuai dengan Keputusan Direktorat Jenderal Pajak KEP-159/PJ/2008 merupakan instansi vertikal pemerintah yang menangani dan mengatur tentang administrasi, penerapan organisasi dan tata kerja perpajakan.

Sumber daya manusia merupakan faktor penting dalam sebuah organisasi. Setiap organisasi akan selalu meningkatkan kualitas sumber daya agar kinerjanya memuaskan. Peningkatan kualitas tersebut merupakan upaya untuk menjadikan pegawai lebih termotivasi dan jelas arah tujuan yang ingin dicapai. Masalah kinerja pegawai merupakan masalah yang perlu diperhatikan organisasi, karena kinerja pegawai akan mempengaruhi kualitas dan kuantitas organisasi dalam menghadapi persaingan 
seiring perkembangan zaman. Sehingga, memiliki SDM (pegawai) yang berkualitas sangat dibutuhkan agar tujuan organisasi dapat tercapai dan dapat meningkatkan kinerja pegawai dalam suatu organisasi.

Apabila SDM memiliki motivasi tinggi, kreatif dan mampu mengembangkan inovasi, kinerjanya akan semakin baik. Namun, kinerja yang baik tidak akan dihasilkan tanpa adanya budaya organisasi dan komitmen organisasional yang mendukung berjalannya organisasi. Budaya organisasi mempengaruhi kinerja pegawai dalam mencapai tujuan organisasi serta menimbulkan kesadaran dan keinginan pegawai untuk berkomitmen pada organisasi, sehingga tercipta loyalitas dan produktivitas kerja yang maksimal dalam mencapai tujuan baik individu maupun organisasi. Budaya organisasi adalah sistem makna bersama yang dianut oleh anggota yang membedakan organisasi dengan organisasi lainnya, dan budaya organisasi mewakili sebuah persepsi yang sama dari anggota organisasi (Robbins; Judge, 2015). Faktor-faktor yang dapat mempengaruhi budaya organisasi adalah kebijakan, gaya dan jati diri perusahaan, nilai, perilaku, kepercayaan serta keadaan yang sangat penting.

Komitmen organisasional adalah bukan hanya kesetiaan pada organisasi, tetapi proses mengekspresikan kepedulian pegawai terhadap organisasi dan prestasi kerja yang tinggi. Komitmen organisasional sebagai suatu sikap pegawai akan menentukan perilakunya sebagai perwujudan dari sikap (Djati; Khusaini (dalam Budianto, 2014)). Faktor-faktor yang dapat mempengaruhi komitmen organisasional adalah personal, pekerjaan, pribadi dan pengalaman kerja.

Kinerja pegawai adalah hasil dari proses yang mengacu dan diukur selama periode waktu tertentu berdasarkan ketentuan atau kesepakatan yang telah ditetapkan sebelumnya (Edison, dkk., 2016:190). Faktor-faktor yang dapat mempengaruhi kinerja pegawai adalah lingkungan internal organisasi, lingkungan eksternal karyawan, tim, sistem dan kontekstual.

Berdasarkan fenomena di lapangan berhubungan dengan kinerja pegawai menjadi hal menarik diperbincangkan pada Kantor Pelayanan Pajak Pratama Bireuen. Dari hasil pengamatan diketahui bahwa budaya organisasi memiliki permasalahan pada Control (pengawasan), dimana cara mengatur pelayanan pada WP (wajib pajak) di kantor pajak ketika pegawai melakukan sosialisasi keluar daerah hanya beberapa pegawai yang tinggal di setiap devisi. Hal ini membuat pegawai yang tinggal tidak dapat mengatur pekerjaan dengan baik disaat wajib pajak datang. Komitmen organisasional memiliki permasalahan pada loyalitas, yaitu tidak ada rasa keterikatan pegawai terhadap divisi yang menjadi tanggung jawabnya. Kinerja pegawai berdampak interpersonal, yaitu pegawai yang jenuh dengan rutinitas yang sama setiap hari tanpa pengembangan tata cara melaksanakan pekerjaannya. Sehingga, menimbulkan masalah pada prosedur kerja yang telah ditetapkan.

Budaya organisasi yang tumbuh pada Kantor Pelayanan Pajak Pratama Bireuen semestinya dapat meningkatkan komitmen pegawainya, sehingga menghasilkan kinerja yang memuaskan. Namun, bentuk komitmen yang muncul bukan hanya bersifat loyalitas yang pasif, tetapi melibatkan hubungan aktif dengan organisasi kerja yang bertujuan memberikan segala usaha demi keberhasilan organisasi, karena yang lebih berkomitmen terhadap organisasinya akan siap melakukan berbagai upaya demi keberhasilan organisasi. Kolaborasi antara budaya organisasi dan komitmen organisasional diharapkan mampu menjadi kesatuan yang kokoh, sehingga menghasilkan kinerja yang baik dan sesuai dengan pencapaian tujuan. Adapun judul penelitian ini adalah "Pengaruh Budaya Organisasi dan Komitmen Organisasional Terhadap Kinerja Pegawai Kantor Pelayanan Pajak Pratama Bireuen”.

\section{METODE PENELITIAN}

Metode penelitian yang digunakan dalam penelitian ini adalah metode kuantitatif. Penelitian dilaksanakan pada Kantor Pelayanan Pajak Pratama Bireuen. Adapun objek penelitian ini adalah pegawai pada Kantor Pelayanan Pajak Pratama Bireuen. Sedangkan sampel penelitian adalah 30 
pegawai pada Kantor Pelayanan Pajak Pratama Bireuen. Data penelitian ini bersumber dari: 1) data primer, yaitu data yang diperoleh secara langsung dari hasil wawancara, observasi dan kuesioner yang disebarkan kepada sejumlah sampel responden sesuai dengan target sasaran dan mewakili seluruh sampel penelitian ini yaitu pegawai pada Kantor Pelayanan Pajak Pratama Bireuen; 2) data sekunder, yaitu data yang diperoleh dari pihak lain secara tidak langsung, memiliki hubungan dengan penelitian yang dilakukan berupa sejarah perusahaan, ruang likup perusahaan, struktur organisasi, buku, literatur, artikel, serta situs di internet. Teknik analisis data menggunakan regresi berganda, koefisien determinasi $\left(\mathrm{r}^{2}\right)$, dan uji hipotesis yaitu uji parsial dan uji simultan.

\section{HASIL DAN PEMBAHASAN}

\section{Hasil Penelitian}

\section{Analisis Regresi Berganda}

Analisis regresi berganda digunakan untuk mengetahui dan menganalisis variabel, pengaruh variabel budaya organisasi dan komitmen organisasional terhadap kinerja pegawai Kantor Pelayanan Pajak Pratama Bireuen atau pengaruh variabel indenpenden terhadap variabel dependen, seperti terlihat pada hasil regresi pengolahan data menggunakan program SPSS versi 22 pada tabel berikut:

Tabel 1. Hasil Analisis Regresi Berganda

\begin{tabular}{|c|c|c|c|c|c|c|c|c|}
\hline \multicolumn{9}{|c|}{ Coefficients $^{\mathrm{a}}$} \\
\hline & \multirow{2}{*}{ Model } & \multicolumn{2}{|c|}{$\begin{array}{c}\text { Unstandardized } \\
\text { Coefficients }\end{array}$} & \multirow{2}{*}{$\begin{array}{c}\text { Standardized } \\
\text { Coefficients }\end{array}$} & \multirow{2}{*}{$\mathrm{t}$} & \multirow{2}{*}{ Sig. } & \multicolumn{2}{|c|}{$\begin{array}{l}\text { Collinearity } \\
\text { Statistics }\end{array}$} \\
\hline & & B & $\begin{array}{c}\text { Std. } \\
\text { Error }\end{array}$ & & & & Tolerance & VIF \\
\hline \multirow{3}{*}{1} & (Constant) & .810 & .525 & & 1.543 & .135 & & \\
\hline & Budaya Organisasi & .306 & .124 & .363 & 2.456 & .021 & .631 & 1.585 \\
\hline & Komitmen Organisasiona & .499 & .143 & .517 & 3.496 & .002 & .631 & 1.585 \\
\hline
\end{tabular}

a. Dependent Variable: Kinerja Pegawai

Berdasarkan tabel di atas dapat disusun persamaan regresi linier berganda sebagai berikut: $\mathrm{Y}=0,810$ $+0,306 X_{1}+0,499 X_{2}$. Dari persamaan di atas dapat diinterprestasikan bahwa:

a. Konstanta $b_{0}(a)=0,810$ artinya jika budaya organisasi (X1) dan komitmen organisasional (X2) nilainya 0 , maka kinerja pegawai nilainya sebesar 0,810 ;

b. Koefisien $\mathrm{b}_{1}=0,306$ artinya jika variabel komitmen organisasional nilainya tetap dan budaya organisasi ditingkatkan $1 \%$, maka kinerja pegawai akan meningkat sebesar 30,6\%;

c. Koefisien $b_{2}=0,499$ artinya jika variabel budaya organisasi nilainya tetap dan komitmen organisasional ditingkatkan $1 \%$, maka kinerja pegawai akan meningkat sebesar $49,9 \%$.

\section{Koefisien Determinasi}

Koefisien determinan digunakan untuk mengukur seberapa besar presentase perubahan atau variabel dependent bisa dijelaskan oleh perubahan atau variasi dari variabel independent. Semakin tinggi nilai koefisien determinasi semakin baik kemampuan variabel independen dalam menjelaskan pengaruhnya terhadap variabel dependen. Hasil pengujian koefisien determinasi terlihat dari nilai adjusted R square pada analisis regresi berganda. Hasil pengujian koefisien determinasi adalah berikut:

Tabel 2. Hasil Pengujian Koefisien Determinasi

\begin{tabular}{c|ccccc}
\hline \multicolumn{7}{c}{ Model Summary $^{\mathrm{b}}$} \\
\hline Model & $\mathrm{R}$ & R Square & Adjusted R Square & Std. Error of the Estimate & Durbin-Watson \\
\hline 1 & $.792^{\mathrm{a}}$ & .627 & .600 & .41197 & 2.020 \\
\hline \multicolumn{7}{l}{ a. Predictors: (Constant), Komitmen Organisasional, Budaya Organisasi } \\
\hline
\end{tabular}

Dari hasil pengujian tersebut, diketahui nilai Adjusted $\mathrm{R}$ Square sebesar 0,600 artinya variabilitas variabel dependen yang dijelaskan oleh variabilitas variabel independen sebesar 60,0\%. Sedangkan 
40\% dapat dijelaskan oleh variabel lain yang tidak termasuk variabel independen. Dari nilai Adjusted R Square 0,600 , maka dinyatakan bahwa besaran pengaruh variabel budaya organisasi dan komitmen organisasional terhadap kinerja pegawai dinyatakan rendah sesuai dengan ketentuan.

\section{Uji Hipotesis}

1. Uji Statistik $T$ (Parsial), digunakan untuk mengetahui apakah variabel budaya organisasi dan komitmen organisasional mempunyai pengaruh terhadap kinerja pegawai.

Untuk mengetahui $\mathrm{t}_{\text {tabel }}$ dimana:

$\mathrm{Df}=\mathrm{n}-\mathrm{k}-1$

Ket: $\mathrm{n}=$ banyak observasi

$\mathrm{k}=$ banyaknya variabel

$\mathrm{Df}=\mathrm{n}-\mathrm{k}-1$

$=30-2-1=27$

Dengan sig 0.05 dan menggunakan penelitian 2 arah (2 tailed). Hasil pengujian hipotesis secara parsial adalah sebagai berikut:

Tabel 3. Hasil Uji Statistik t Coefficients

\begin{tabular}{cccc}
\hline Model & t hitung & t tabel & Sig. \\
\hline (Constant) & 1,543 & &, 135 \\
BO & 2,456 & 1,70 &, 021 \\
KO & 3,496 & &, 002 \\
\hline
\end{tabular}

a. Dependent Variabel: Kinerja Pegawai

Sumber: Data Primer Olahan 2020

Berdasarkan tabel di atas, diketahui kedua variabel independen berpengaruh signifikan terhadap variabel dependen, yaitu:

1. Budaya Organisasi

Dari hasil perhitungan secara parsial variabel budaya organisasi berpengaruh terhadap variabel kinerja pegawai, ditunjukkan dengan besarnya nilai $t_{\text {hitung }}$ sebesar 2,456 dan nilai $t_{\text {tabel }}$ sebesar 1,70 artinya 2,456>1.70 dengan nilai probabilitas sebesar 0,021. Sehingga, disimpulkan bahwa budaya organisasi berpengaruh terhadap kinerja pegawai, yang menandakan bahwa $\mathrm{H}_{\mathrm{o}}$ ditolak dan $\mathrm{H}_{\mathrm{a}}$ diterima, artinya budaya organisasi berpengaruh terhadap kinerja pegawai pada Kantor Pelayanan Pajak Pratama Bireuen yang berarti $\mathrm{H}_{1}$ diterima.

2. Komitmen Organisasional

Dari hasil perhitungan secara parsial variabel komitmen organisasional berpengaruh terhadap variabel kinerja pegawai, ditunjukkan dengan besarnya nilai $t_{\text {hitung }}$ sebesar 3,496 dan nilai $t_{\text {tabel }}$ sebesar 1,70329 artinya 3,496>1.703 dengan nilai probabilitas sebesar 0,002. Sehingga, disimpulkan bahwa komitmen organisasional berpengaruh terhadap kinerja pegawai, yang menandakan bahwa $\mathrm{H}_{\mathrm{o}}$ ditolak dan $\mathrm{H}_{\mathrm{a}}$ diterima, artinya komitmen organisasional berpengaruh terhadap kinerja pegawai pada Kantor Pelayanan Pajak Pratama Bireuen yang berarti $\mathrm{H}_{2}$ diterima.

2. Uji Statistik F (Simultan), untuk mengetahui variabel independen terhadap variabel dependennya secara bersama-sama ( simultan). Melihat nilai $\mathrm{f}_{\text {tabel }}$ sebagai berikut: df $1=\mathrm{k}-3$ dan df $2=\mathrm{n}-\mathrm{k}$ (df1 $=3-1=2, \mathrm{df} 2=30-3=27$ ), maka hasil uji statistik $\mathrm{F}$ ditunjukkan terlihat sebagai berikut:

Tabel 4. Hasil Regresi Uji F

\begin{tabular}{ccccccc}
\hline \multicolumn{7}{c}{ ANOVA $^{\mathrm{a}}$} \\
\hline \multirow{3}{*}{1} & Model & Sum of Squares & df & Mean Square & F & Sig. \\
\cline { 2 - 7 } & Regression & 7.717 & 2 & 3.859 & 22.735 & $.000^{\mathrm{b}}$ \\
\cline { 2 - 7 } & Residual & 4.583 & 27 & .170 & & \\
\cline { 2 - 7 } & Total & 12.300 & 29 & & \\
\hline
\end{tabular}

a. Dependent Variable: Kinerja Pegawai

b. Predictors: (Constant), Komitmen Organisasional, Budaya Organisasi 
Dari hasil uji $F$ dengan nilai $F_{\text {hitung }}$ sebesar 7,717 dan nilai $F_{\text {tabel }}$ sebesar 3,35 dengan nilai signifikan 0,000, maka $\mathrm{H}_{\mathrm{o}}$ ditolak dan $\mathrm{H}_{\mathrm{a}}$ diterima. Hal ini menunjukkan secara simultan variabel independen berupa budaya organisasi dan komitmen organisasional berpengaruh terhadap kinerja pegawai, artinya besar kecilnya variabel independen secara simultan mempengaruhi kinerja pegawai tahun mendatang.

\section{Pembahasan}

\section{Budaya Organisasi Terhadap Kinerja Pegawai Pada Kantor Pelayanan Pajak Pratama Bireuen}

Budaya organisasi adalah sistem makna bersama yang dianut oleh anggota, yang membedakan organisasi tersebut dengan organisasi lain dan mewakili persepsi yang sama dari anggota organisasi. Hal ini sesuai dengan hasil penelitian yang didapatkan bahwa terdapat pengaruh budaya organisasi terhadap kinerja pegawai di Kantor Pelayanan Pajak Pratama Bireuen, terlihat dengan besarnya nilai $t_{\text {hitung }}$ sebesar 2,456 dan nilai $t_{\text {tabel }}$ sebesar 1,70 artinya 2,456 $>1.70$ dengan nilai probabilitas sebesar 0,021 . Hal tersebut menandakan bahwa $\mathrm{H}_{\mathrm{o}}$ ditolak dan $\mathrm{H}_{\mathrm{a}}$ diterima dan terdapat pengaruh positif dari hasil regresi berganda dengan koefisien $b_{1}=0,306$ artinya jika variabel budaya organisasi nilainya tetap dan komitmen organisasional ditingkatkan $1 \%$ maka kinerja pegawai akan meningkat $0,306 \%$.

\section{Pengaruh Komitmen Organisasional Terhadap Kinerja Pegawai Pada Kantor Pelayanan Pajak Pratama Bireuen}

Komitmen organisasional bukan hanya kesetiaan pada organisasi, tetapi proses mengekspresikan kepedulian pegawai terhadap organisasi dan prestasi kerja yang tinggi. Komitmen organisasional sebagai suatu sikap pegawai akan menentukan perilakunya sebagai perwujudan dari sikap tersebut. Hal ini sesuai dengan hasil penelitian yang didapatkan bahwa terdapat pengaruh komitmen organisasional terhadap kinerja pegawai di Kantor Pelayanan Pajak Pratama Bireuen, terlihat dengan besarnya nilai $t_{\text {hitung }}$ sebesar 3,496 dan nilai $t_{\text {tabel }}$ sebesar 1,70 artinya 3,496 $>1.70$ dengan nilai probabilitas 0,002 . Hal tersebut menandakan $\mathrm{H}_{\mathrm{o}}$ ditolak dan $\mathrm{H}_{\mathrm{a}}$ diterima dan terdapat pengaruh positif dari hasil regresi berganda dengan koefisien $b_{2}=0,499$ artinya jika variabel komitmen organisasional nilainya tetap dan budaya organisasi ditingkatkan $1 \%$ maka kinerja pegawai akan meningkat $0,499 \%$.

\section{Pengaruh Budaya Organisasi dan Komitmen Organisasional Terhadap Kinerja Pegawai Pada Kantor Pelayanan Pajak Pratama Bireuen}

Budaya organisasi adalah nilai-nilai dasar organisasi yang menjadi landasan bersikap, berperilaku dan bertindak bagi anggota organisasi. Sedangkan, komitmen organisasional adalah keadaan karyawan memihak kepada perusahaan tertentu dan tujuannya, serta berniat memelihara keanggotaannya dalam perusahaan itu. Maka, komitmen organisasional berkaitan dengan keinginan karyawan yang tinggi untuk berbagi dan berkorban untuk perusahaan. Adapun kinerja karyawan adalah hasil dari proses yang mengacu dan diukur selama periode waktu tertentu berdasarkan ketentuan atau kesepakatan yang telah ditetapkan sebelumnya. Hal ini sesuai dengan hasil penelitian yang didapatkan bahwa, terdapat pengaruh budaya orgnisasi dan komitmen organisasional terhadap kinerja pegawai di Kantor Pelayanan Pajak Pratama Bireuen yang dibuktikan dengan nilai $F_{\text {hitung }}$ sebesar 7,717 dan nilai $F_{\text {tabel }}$ sebesar 3,35 dengan nilai signifikan 0,000 .

\section{SIMPULAN}

Berdasarkan hasil dan pembahasan penelitian dapat disimpulkan bahwa: 1) budaya organisasi secara parsial berpengaruh terhadap kinerja pegawai Kantor Pelayanan Pajak Pratama Bireuen dengan nilai $t_{\text {hitung }}$ sebesar 2,456 dan nilai $t_{\text {tabel }}$ sebesar 1,70 artinya 2,456 $>1,70$ dengan nilai probabilitas sebesar 0,021, menandakan bahwa $\mathrm{H}_{\mathrm{o}}$ ditolak dan $\mathrm{H}_{\mathrm{a}}$ diterima, maka terdapat pengaruh positif dari budaya organisasi terhadap kinerja pegawai; 2) komitmen organisasional secara parsial berpengaruh terhadap kinerja pegawai Kantor Pelayanan Pajak Pratama Bireuen dengan nilai $t_{\text {hitung }}$ sebesar 3,496 dan nilai $t_{\text {tabel }}$ Sebesar 1,70 artinya 3,496>1,70 dengan nilai probabilitas sebesar 0,002, menandakan bahwa $\mathrm{H}_{\mathrm{o}}$ 
ditolak dan $\mathrm{H}_{\mathrm{a}}$ diterima, maka terdapat pengaruh positif dari komitmen organisasional terhadap kinerja pegawai; 3) budaya organisasi dan komitmen organisasional secara simultan berpengaruh terhadap kinerja pegawai Kantor Pelayanan Pajak Pratama Bireuen dengan nilai $F_{\text {hitung }}$ sebesar 7,717 dan nilai $\mathrm{F}_{\text {tabel }}$ sebesar 3,35 dengan nilai signifikan 0,000, menandakan bahwa $\mathrm{H}_{\mathrm{o}}$ ditolak $\mathrm{H}_{\mathrm{a}}$ diterima.

\section{REFERENSI}

Amstrong, M., Baron, F. 2016. Manajemen Kinerja. Jakarta: Erlangga.

Arikunto, Suharsimi. 2012. Prosedur Penelitian. Jakarta: Rineka Cipta.

Budianto, Fendy. 2014. Pengaruh Keselamatan dan Kesehatan Kerja Terhadap Komitmen Organisasional Karyawan pada Bagian Produksi PT Sumber Kencana di Bojonegoro. AGORA. Vol.2, No. 1, Hlm. : 1-6.

Dani, A. K. 2016. Hubungan Komunikasi Organisasi dan Komitmen Organisasi dengan Manajemen Konflik pada Guru di Sekolah Islam Bunga Bangsa Samarinda. Jurnal Psikologi, 4 (2), 2477-2674.

Debby, Wine Simatupang. 2015. Hubungan Gaya Kepemimpinan Transformasi dengan Komitmen Organisasional PT. PLN (PERSERO) Distribusi Bali. Yogyakarta: Universitas Gajah Mada.

Edison., dkk. 2016. Manajemen Sumber Daya Manusia. Bandung: Alfabeta.

Robbins, S.P., Judge, T.A. 2015. Perilaku Organisasi. Jakarta: Salemba Empat.

Siregar, Syofian. 2013. Metode Penelitian Kuantitatif. Jakarta: Fajar Interpratama Mandiri.

Sudarmanto. 2009. Kinerja dan Pengembangan Kompetensi SDM (Teori, Dimensi dan Implementasi) dalam Organisasi. Yogyakarta: Pustaka Pelajar.

Sugiyono. 2012. Metode Penelitian Kuantitatif, Kualitatif dan $R \&$ D. Bandung: Alfabeta. 2015. Metode Penelitian Manajemen. Bandung: Alfabeta.

Tampubolon, Manahan P. 2008. Perilaku Keroganisasian: Perspektif Organisasi Bisnis. Bogor: Ghalia Indonesia.

Tiara, P.U., Djamhur, H.H., Nayati, Utami. 2016. Pengaruh Budaya Organisasi Terhadap Komitmen Organisasional dan Kinerja Karyawan (Studi pada Karyawan Pabrik Gondorukem dan Terpentin Sukun Perum Perhutani Kesatuan Bisnis Mandiri Industri Gondorukem dan Terpentin II, Ponorogo). Jurnal Administrasi Bisnis (JAB) Vol. 37 No. 2 Agustus 2016.

Wardiah. 2016. Teori Perilaku dan Budaya Organisasi. Bandung: Pustaka Setia.

Wibawa. 2015. Manajemen Kinerja. Jakarta: Rajagrafindo Persada.

Wirawan, 2015. Evaluasi Kinerja Sumber Daya Manusia. Jakarta: Salemba Empat.

Yonathan, S.K., Eddy, M.S. 2014. Pengaruh Budaya dan Komitmen Organisasional terhadap Kinerja Karyawan pada PT Rajawali Citramas Mojokerto. AGORA Vol. 2. No. 1 (2014).

Pabundu, Tika. 2010. Budaya Organisasi dan Peningkatan Kinerja Perusahaan. Jakarta: Bumi Aksara. 